
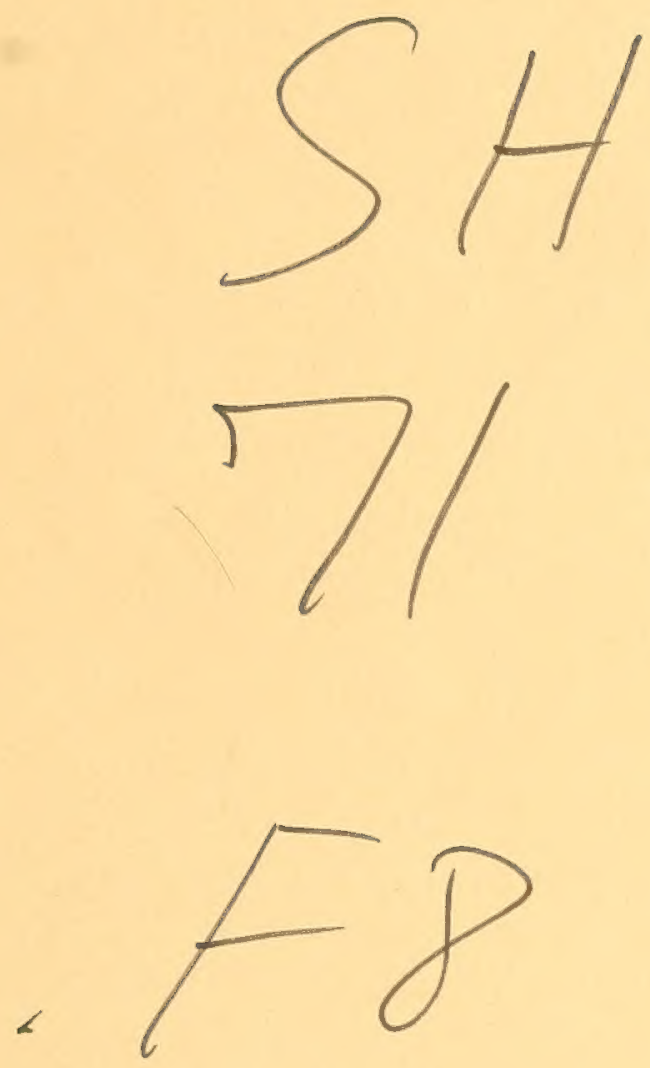


$$
\begin{aligned}
& S H \\
& 71 \\
& F 8
\end{aligned}
$$




\title{
CAUSES OF DEGENERATION OF AMERICAN TROUTS IN AUSTRIA
} 2

\author{
By Johann Franke
}

Director of the Fish-Culture Establishment at Studenec and Secretary of the Fishery Committee for the District of Krain

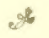

Paper presented before the Fourth International Fishery Congress held at Washington, U. S. A., September 22 to 26, 1908

BULLETIN OF THE BUREAU OF FISHERIES : : : : : : VOL. XXVIII, P. 983-989

Document No. 699 : : : : : : : : : : : : : : : : : lssued April, 1910 


$$
\begin{gathered}
5+1 \\
4^{8}
\end{gathered}
$$

$A B=251910$

강

$\therefore$ 


\section{CAUSES OF DEGENERATION OF AMERICAN TROUTS IN AUSTRIA.}

$$
x
$$

By JOHANN FRANKE,

Director of the Fish-Culture Establishment at Studenec and Secretary of the Fishery Commission for the Province of Krain.

$*$

[Translated from the German.]

I have had to do with the feeding of rainbow and brook trout in ponds and inclosures for seventeen years. I have, had experience with rainbow trout in clear running water for thirteen years, and much more thoroughly and in detail with brook trout for eight years.

The two species are excellent as breeders, first class and far superior to the native trout (Salmo fario). They can consume an astonishing amount of food, their appetite is extraordinarily persistent, and they repay the voracious feeding by astoundingly rapid growth; they remain well, keep their beautiful vivid coloring, and yield excellent spawn, even "red eggs" when in the proper condition and in surroundings suitable to salmonoids. The view that the degeneration of this fish, wherever it has occurred, is a result of natural tendencies and the qualities of our water, and that the degeneration was to be expected in the nature of things, I entirely repudiate, for I am convinced that the degeneration is the effect of artificial conditions unsuitable to salmonoids.

The true reason for the degeneration of these fishes is in faulty methods on the part of the fish culturists. The brook trout especially has been greatly discredited in Vienna and in other places, being pronounced very weak, its flesh distasteful, etc. This may have been true, as it is being bred in a most irresponsible way, the fish being given all kinds of impossible food in order to produce it quickly and cheaply. There is great competition in the sale of spawn, small producers selling not directly to the users but to agents who advertise not only hundreds of thousands but even a million or two as being their own product. The producer does not obtain even 3 crowns ( 60 cents) per thousand in many cases. Much of this has already been published in German special papers 
discussing the subject of degeneration, and many astonishing facts have been brought out. Good eggs are cheap even at 5 crowns (or \$I), and a breeding establishment can be maintained properly and on a businesslike footing only when the eggs bring ro crowns. At present the fishes are bred down into a wretched condition. The much desired eggs from America will degenerate in the same way if the method of breeding for reproduction is not henceforth different from that which has prevailed.

The unfavorable conditions surrounding the American trouts in this country, brought to my knowledge through experience during the long period I have mentioned, I have found to be due partly to inadequate insight into many essentials of fish culture, and partly also to things which could not be changed. I have been able, however, to acquaint myself with some of the phenomena of degeneration and their causes, and some of them I have successfully combated.

I consider the principal causes of degeneration to be:

I. Unhealthy pond bottom, i. e., bottom on which ooze and remnants of food as well as excretions accumulate for months at a time. The slower the current and the longer required for the water to run off, the more dangerous grow the conditions even at a low temperature of from $10^{\circ}$ to $13^{\circ}$ centigrade. The planting of water cress on the bottom and the introduction of carps and perches is not sufficient by any means, as these fish do not wallow in the ooze at temperatures of $10^{\circ}$ to $13^{\circ}$. For example: A spring pond having an area of I 40 square meters and a depth of from 60 to roo centimeters was stocked about the end of August with I,500 rainbow trout of the same year, and disease appeared in January, r897; it was impossible to drain the basin without lowering the level of the water in the principal pond and disturbing the entire establishment. The ooze was taken out by means of a strong pump and a rubber hose; in some places it was black and bad smelling. The disease disappeared entirely a few days later. After this I succeeded in saving the one-year-old fishes in low-water ponds with weak currents by means of frequent pumping out of the ooze and by keeping the bottom clean.

2. Substitutes for the natural food. Fresh flesh of fishes (I had only freshwater fishes) must be considered as natural by the effect produced, even if it is cooked. I never succeeded in keeping the trout healthy for a long period when using substitutes (a mixture of fresh blood cooked with shrimp meal, or the spawn of sea fishes, or fish meal-Ideal brand - and flour as a binding material) without an abundant addition of fresh fish. Within two and at the latest within three months there were traces of change of color to a darker, dimmer hue with a bluish tinge, more noticeable in the many-colored brook than in the darker rainbow trout. If they reached the blackish-hue stage they could not be saved. In such cases live natural food without any adulteration proved the best of remedies. 
Latest example from the current year: Spring pond of 90 square meters, good depth, and slow current of the water at a temperature of $10^{\circ} \mathrm{C}$.; there were in the middle of February 400 beautiful rainbows from a lot of the previous year, of which 950 had been taken out in apprehension of lack of water in winter and sent to other places in November. The suspicious looking bluish tinge was already awakening our anxiety; there was danger in delay, but the best remedy was natural food. A broad flat pool with spring water flowing through it, all covered with vegetation and algæ, had become free of ice. Here were caught by means of a fine dip net a mass of various small animal life, small and large larvæ of mosquitoes, crawfish, woodlice, small fishes, and even bullheads. The small animal forms came slowly to the surface from the thick forest of vegetation and dirt and were caught up. The entire mixture was then taken to the shallow water near the bank of the pond, where the trout themselves took the food out of this mixture. The pool supplied ample food year after year, thus saving the fishes more than once, though diminishing in abundance each year toward the month of May. Seven of these rainbows died, but all the remaining seemed well and acquired within three months their normal aspect, which they kept. To be sure, they were given no more food substitutes. The last 75 fishes were sent away in July; they weighed each I 3 kilograms and stood very well the transportation of $6 \frac{\mathrm{I}}{2}$ hours, as did also those which were sent away earlier.

As long as the materials for the diet of the small fry and young fishes contained crustaceans and fresh fish, the breeding and rearing went on exceedingly well, but in winter, with the forced use of substitutes, or in proportion to the lack of fresh fishes, the trouble began.

3. Insufficient flow of water through the ponds. The two large ponds have an old accumulation of ooze at the bottom some 20 to Ioo centimeters deep; can be emptied only down to five-sixths of their contents at best, as the entire system of springs of the establishment flows through these. This, which it is impossible to correct, is surely an evil, but it had no apparent bad effect upon the larger salmonoids and the breeding fishes so long as the flow was abundant. When the supply grew less, in 1897-98, there appeared again the exophthalmia and the "staggers" now and then. With the decrease of springs these phenomena grew more frequent, several of the native trout (fario) became miserably thin, and several rainbow trout yielded spawn that could not be used. In I904 the establishment went through two or three months without the flow of the springs, and in summer the surface water of the principal ponds at a certain distance from the inflow of the water had a temperature of $18^{\circ}$ and near the exit a temperature of $21.2^{\circ} \mathrm{C}$. At that time the water was calm, for what current could be expected from a couple of second liters in an area of $13 / 4$ hectares? The water near the bottom was cooler by some $2^{\circ}$ to $4^{\circ}$, and the trout lay there 
in lethargy and without appetite; only the roaches and a few carp swam slowly about. Good spawn was obtained only in ponds where there was an outflow of springs; there were but few brood fish in the places where formerly could be found some ioo kilograms; and good roe fishes were in still smaller number. In addition to this symptom of degeneration there were others in an increased degree. Anæmia, however, did not appear in the rainbow or brook trout.

No food substitute whatever was given to the fish in the principal pond, in order to forestall a beginning of degeneration. This, however, was without avail. The regulation of the course of the principal river of the country gradually drained away the living water supply of the establishment; the springs coming from the great subterranean stream of the Laibach field went dry, and we were forced to abandon the locality in July of this year.

It is impossible to demonstrate in a more striking way than this the necessity of a good flow of water, one of the three conditions-infected bottom of ponds, continuous use of substitute foods, and insufficient flow of water-which brings about phenomena of degeneration, the more rapidly and in so much the higher degree if two or all three causes are operating at the same time.

And what about native trout? I would ask only when and where has there been observed in this fish any greater power of resistance against the abovementioned causes of degeneration? It is not less sensitive than the brook trout and considerably more so than the rainbow.

As to the American trouts in running streams I know of only one drawback to the rainbow, namely, that there is no reason to suppose that it will remain and make a constant abode in particular waters, or that it will immediately leave the abode of its youth; water seemingly of the same character was in reality quite different. In two cases the fry developed in four years into mature fishes. The lingering of the rainbow in certain waters has astonished us as often as its disappearance from the same localities.

The brook trout shows more tendency to remain. In waters where food is abundant this fish surpasses even the rainbow in rapid growth. Contrary to the general opinion that it must have cool water, I saw this fish thrive one summer in water having a temperature of $18^{\circ}$ to $20^{\circ} \mathrm{C}$. In small creeks, poor in food, it scarcely thrives as well as the native fario. In the Stara Voda, which stream I had under my control from I90I to I908, it grew to be the principal fish after the first introduction as small fry, while only a few of the rainbow trout had remained there. The native fario, which was already there and did well, remained far behind the fontinalis in numbers and in rapidity of growth. Only during the last two years, when the stream suffered, like the establishment 
of Studenec, from lack of water and of current, the fario stood it better than the fontinalis and appeared in greater numbers than the latter.

Up to the time when I began to control this stream I knew nothing about the possibilities of the brook trout. Introduced into the stream in March, I gor, as small fry which had not yet been fed, several fishes were caught by me in August weighing from 0.3 to 0.5 kilogram, while the largest weighed 0.65 kilogram; they were fat and round, beautifully tinted, and their flesh was exquisite. The spawn (spawning season from November 7 to December i5) proved good in the hatchery, although the eggs were smaller than those of older fishes. Three-year-old fishes weighed 0.75 kilogram. I never dared to let them grow older through fear of their being stolen.

My regret over the drainage of this stream is greater than for the ruin of the fish-culture establishment. 

Hollinger Corp. pH 8.5 